九州大学学術情報リポジトリ

Kyushu University Institutional Repository

\title{
Investigation on the Performance of Pipe Roof Method Adjacent to the Underground Construction
}

\section{Ma, Peng}

Department of Earth Resources Engineering, Faculty of Engineering, Kyushu University

Shimada, Hideki

Department of Earth Resources Engineering, Faculty of Engineering, Kyushu University : Professor

\section{Sasaoka, Takashi}

Department of Earth Resources Engineering, Faculty of Engineering, Kyushu University : Associate Professor

Hamanaka, Akihiro

Department of Earth Resources Engineering, Faculty of Engineering, Kyushu University : Assistant Professor

他

http://hdl. hand le. net/2324/4479700

出版情報: Geotechnical and Geological Engineering, 2021-02-27. Springer バージョン：

権利関係 : 


\title{
Investigation on the Performance of Pipe Roof Method Adjacent to the Underground Construction
}

\author{
Peng Ma ${ }^{\mathrm{a}}$, Hideki Shimada ${ }^{\mathrm{a} *}$, Takashi Sasaoka ${ }^{\mathrm{a}}$, Akihiro Hamanaka ${ }^{\mathrm{a}}$, Tumelo K.M Dintwe ${ }^{\mathrm{a}}$, \\ Donjiang $\operatorname{Pan}^{\mathrm{b}}$
}

${ }^{a}$ Department of Earth Resources Engineering, Faculty of Engineering, Kyushu University, Fukuoka 819-0395, Japan

b State Key Laboratory of Shield Machine and Boring Technology, China Railway Tunnel Group Co., Ltd., Zhengzhou 450001, China.

\begin{abstract}
In this paper, the behaviour of the pipe roof method with different pipe roofs disposition schemes including the pipe roof gate system and L-shaped system is discussed in terms of ground settlement reduction in the condition of underground space construction adjacent to the existing structure by using numerical simulation method. Considering the construction sequences of parallel underground tunnels with rectangular cross sections, the appropriate parameters and ground response characteristics of the corresponding pipe roof methods are evaluated by the ground surface displacement. The results indicated that the construction impacts from new buildings can be reduced by the pipe roof method. However, the theoretical performance of pipe roofs is highly dependent on the spacing between two structures. Generally, the L-shaped system is more effective in case of the distance $(D)$ that is less than or equal to $1 / 2$ width of box culvert $(R)$ under the condition of a new structure constructed nearby the existing building. When two structures are constructed simultaneously, the excavation and the construction of structures influence each other reciprocally. The conclusions could provide a reference for the pipe roof method with the application scenario of adjacent building protection.
\end{abstract}

Keywords: Pipe roof method, Adjacent construction, Settlement, Pipe jacking, Finite element method

\section{Introduction}

In Japan, a variety of underground infrastructures including underpass and subways, water and

\footnotetext{
* Correspondence.
}

Email: shimada18r@mine.kyushu-u.ac.jp Tel:+81 070-4088-2046 Fax: +81-92-802-3368

Address: R519, Department of Earth Resources Engineering, 744 Motooka, Nishi-ku, Fukuoka 819-0395, Japan 
sewage systems, electric and gas pipelines, and comprehensive pipe rack have been constructed through trenchless technologies (Japan Tunnelling Association 1995; Shimada et al. 2004; Khazaei et al. 2006). In which, pipe jacking method, as one of the trenchless technologies, has broad adaptability for constructing underground pipelines in various geological conditions (Marshall and Milligan 1998; Oliver et al. 2006). With this method, the disturbance from the construction impact to existing facilities on the surface as well as in the underground could be greatly reduced during the construction process. Therefore, the pipe jacking method is appearing in various forms in underground space construction for a minor construction impact and acceptable ground surface settlement, such as the pipe roof method.

Many types of research have investigated the basic parameters of pipe roof method with laboratory experiments and field tests to improve the engineering performance of pipe roofs (Xiao et al. 2005; Peng et al. 2016). Some mechanical explanations and numerical simulations were done to explain the working mechanism and try to find a way to propose the reasonable parameters determination method under different geological conditions (Bae et al. 2005; Wang and Ha 2008). What's more, the application scenarios for the pipe roof method is also expanding to deep ground condition and cold region (Hu et al., 2017; Xiang, 2017). However, in general, it is still mainly concentrated in the direction of pre-support for large underground tunnels construction. Nowadays, with the utilization of the underground space expanding, some new spaces need to be constructed in the crowded underground urban area, leading to the necessity of the protection of existing buildings located nearby (Coller and Abbott 1994; Fang and Sun 2000; Jia et al. 2018). In other words, it requires to control the ground surface settlement during the construction, but also preserve the adjacent structures to the greatest extent (Hisatake and Ohno, 2008; Volkmann and Schubert, 2007). However, based on the continuity of the underground stress field, new construction will inevitably impact on the existing structures, which is difficult to avoid in a narrow space (Wang et al. 2015).

From the perspective of the superposition effect from successive constructions, some engineering cases show that the protection of nearby structures is still limited. Yang Sun (2019) investigated the ground response and construction impact by monitoring the displacement and pore pressure of the surrounding ground during the construction of two adjacent underground pedestrian passages constructed by pipe jacking method successively. The project was conducted under a major urban expressway with a small space of $0.5 \mathrm{~m}$. In terms of the ground surface settlement, the greatest surface settlement on the tunnel axis was $55 \mathrm{~mm}$ after the first pipeline jacked, when the second pipeline jacked, the surface 
settlement was up to $155 \mathrm{~mm}$ and $300 \mathrm{~mm}$ above the first jacked pipeline and second jacked pipeline, respectively, due to the superposition effect from both jacking construction. It far exceeded the requirement of highway settlement, causing serious traffic and environmental problems (Wang et al. 2019). In the meantime, the friction force during the second pipeline was increased due to the redistribution of the effective stress. Therefore, pipe roof method is supposed to be an effective way to minimize the construction impacts on the ground surface and adjacent structures.

Consequently, it is necessary to discuss the effect of the pipe roof method in the protection of neighbouring structures using the numerical method. However, there are few application cases of the pipe roof method for the protection of existing underground buildings adjacent to the new structure. Similarly, few reports and/or scientific publications are available on the suppressive effects by pipe roof on adjacent structures when a new tunnel is constructed. For this reason, this paper discusses the effects of the pipe roof method in light of the ground surface settlement with three-dimension numerical analysis. Two rectangular pipelines with the pipe roofs were simulated, and the performance of the pipe roof method with different pipe roofs disposition schemes including the gate system and L-shaped system were investigated by considering the construction sequences and appropriate parameters.

\section{Numerical model setup}

The preservation of existing buildings during the construction of a new underground structure nearby is a serious challenge. Pipe roof method could be used when two underground structures are constructed close together. Thus, the basic disposition of pipe roofs and optimal design should be the first concern before construction. Key factors like the diameter of the roof pipes and distance between the main tunnels are imperatively impacting the performance of the pipe roof method, as well as the economical cost. As aforementioned, the numerical analysis was conducted with a three-dimensional finite element method to clarify the effects of the pipe roofs disposition on the ground settlement and the adjacent building.

The numerical model was built based on a potential engineering project in Japan, the main underground structure constructed by box culverts was defined with a $6.4 \mathrm{~m}$ in height and $7.4 \mathrm{~m}$ in width. Fig. 1 illustrates an overview of the calculation model. The width and height of the model cross-section were established to be $80 \mathrm{~m} \times 40 \mathrm{~m}$ and with a length of $60 \mathrm{~m}$ in the axis direction, and a threedimensional eight-node hexahedron element (C3D8R) was adopted in this simulation to achieve better effectiveness. The left and right boundaries are about 5 times the main tunnel width to avoid the boundary 
effect (Yen and Shou 2015). Meanwhile, the boundary conditions are kept consistent in different simulation schemes to minimize its influence on the simulation results. The main rectangular tunnel extends $60 \mathrm{~m}$ with $7.5 \mathrm{~m}$ overburden from the ground surface. In the viewpoint of roof pipelines, the diameters are $800 \mathrm{~mm}$ with a total length of $60 \mathrm{~m}$ constructed by the pipe jacking method. The length of each pipe string is $900 \mathrm{~mm}$. Furthermore, the thickness of the tail void was $20 \mathrm{~mm}$. The simulation process was assumed as the actual construction of the pipe roof method constructed by the slurry pipe jacking. The initial stress state corresponds to gravitational loading. The steel pipes of the pipe roof are modelled with shell structural element, and its properties were listed in Table 1. The tail void is modelled in $20 \mathrm{~mm}$. Considering the consolidation of the lubricant injected into the tail void, the mechanical properties were changing over time, as shown in Table 2. The soil mechanical parameters properties used in this numerical model are presented in Table 3. The elastic parameters required for the model are as described in Tables 1-3. The property of mortar was assigned based on mortar fill in the pipe and rigidity of the pipe (Jia et al. 2018). In this 3D analysis model, the direction of jacking is defined as Z-axis origin, and the survey line is located $30 \mathrm{~m}$ from $\mathrm{X}$-axis with the assumption that the displacement of the ground surface has reached the maximum at this line. Additionally, the point $\mathrm{O}$ is set as the centre of observation.
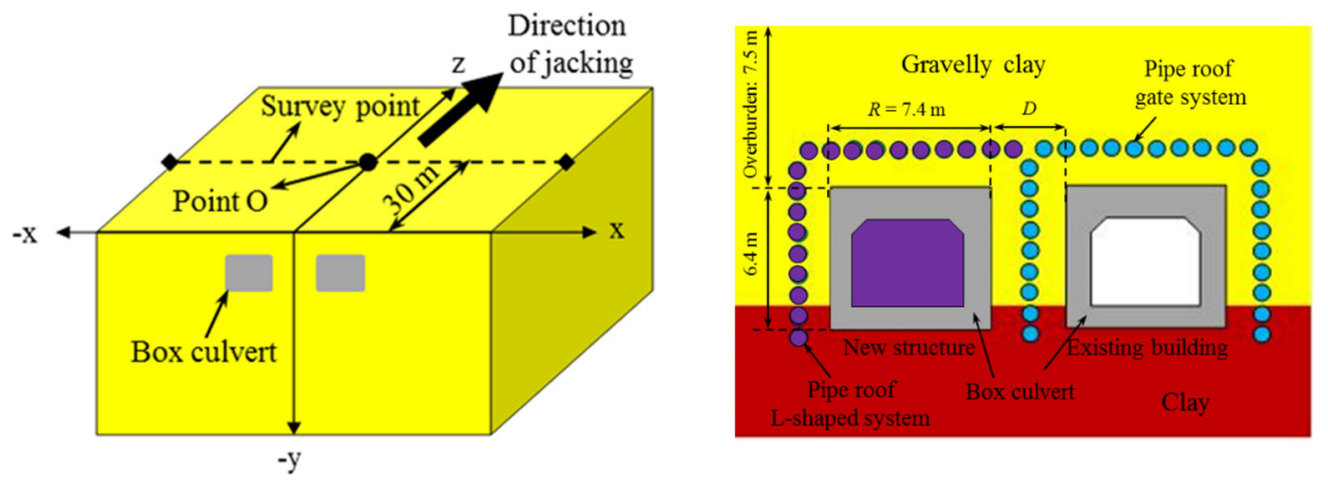

Fig. 1 Overview of the 3D finite element model: (a) model structure; (b) pipe roof gate system and pipe roof L-shaped system.

Table 1 Mechanical properties of steel pipe used in analysis

\begin{tabular}{cc}
\hline Parameters & Values \\
\hline Young's modulus (MPa) & 210000 \\
Poisson's ratio & 0.25 \\
Thickness (mm) & 12 \\
\hline
\end{tabular}

Table 2 Lubricant properties used in simulation

\begin{tabular}{ccccc}
\hline & & Young's modulus (MPa) & Poisson's ratio & Density (MN/m3) \\
\hline \multirow{6}{*}{ Lubricant } & After injection & 0.00098 & 0.49 & 0.022 \\
& 7 days passed & 0.23 & 0.41 & 0.022 \\
& 14 days passed & 0.33 & 0.35 & 0.022 \\
& 28 days passed & 0.43 & 0.3 & 0.022 \\
\hline
\end{tabular}


Table 3 Soil Mechanical properties

\begin{tabular}{cccccc}
\hline Type & $\begin{array}{c}\text { Young's modulus } \\
(\mathrm{MPa})\end{array}$ & Poisson's ratio & $\begin{array}{c}\text { Friction angle } \\
\left.{ }^{\circ}\right)\end{array}$ & $\begin{array}{c}\text { Cohesion } \\
(\mathrm{MPa})\end{array}$ & $\begin{array}{c}\text { Density } \\
\left(\mathrm{kg} / \mathrm{m}^{3}\right)\end{array}$ \\
\hline $\begin{array}{c}\text { Gravelly } \\
\text { clay }\end{array}$ & 19 & 0.4 & 20.7 & 0.05796 & 0.02 \\
$\begin{array}{c}\text { Clay } \\
\text { Mortar }\end{array}$ & 17 & 0.35 & - & - & 0.18 \\
\hline
\end{tabular}

For the construction of a new tunnel nearby existing buildings, besides considering the normal pipe roof method, which is referred to as gate system (see in Fig. 1), the L-shaped system is also considered for comparison. In this simulation, the effect of the pipe roof gate system and the L-shaped system on the ground surface subsidence above the tunnel was investigated. In which the L-shaped means that the section shape of the installation pipelines of this system looks like the letter "L". The construction sequence of main tunnels could represent the adjacent existing structures, while the subsidence of the ground was considered as an indicator for performance evaluation in this simulation, which was discussed under different gap among new tunnel or structure and existing neighboring building. As for the construction sequence, three cases were simulated: (1) new structure is constructed nearby existing building; (2) two structures are constructed sequentially; and (3) two structures are constructed simultaneously. For a better description, hereafter the distance among main structures and width of tunnels are defined as D and R, respectively.

\section{Results and discussion}

\subsection{A new structure constructed nearby the existing building}

In this section, numerical analysis was carried out to investigate the displacement of the ground surface under the gate system and the L-shaped system. The investigation was considering the different distances between the new structure and the existing building. Specifically, the distance $(D)$ between the new structure and existing building, was set for $1 / 4 R, 1 / 2 R, 3 / 4 R, R$, and $5 / 4 R$, containing most of the feasibility in the actual construction. According to the field experience and empirical formula on-site (Xiao et al. 2019), the disturbance range of underground tunnels is $0.3-0.5 R$, in which $R$ is the tunnel's diameter. By setting $0.25 R$ as the increment, the various situations within and outside the disturbance range were fully considered for new tunnel construction. Besides, the relationship between the surface deformation and the distance $(D)$ was investigated by using the tunnel width $R$ as a reference to adjust the distance $D$ regularly, so that the simulation results can be referenced in other similar situations. Meanwhile, with the changing of the distance among structures, there are two special circumstances need 
to be considered: (1) A complete pipe roof gate system cannot be installed when $D$ is equal to $1 / 4 R$ due to insufficient space between the new structure and the existing building; consequently, only pipe roof L-shaped system was analysed in this situation; (2) the number of roof pipelines of gate system is greater than that of L-shaped system when $D$ is greater than $5 / 4 R$; obviously, the gate system is more expensive than that of the L-shaped system in terms of the amount of pipe consumption. Fig. 2 illustrates the numerical models of the gate system and the L-shaped system.

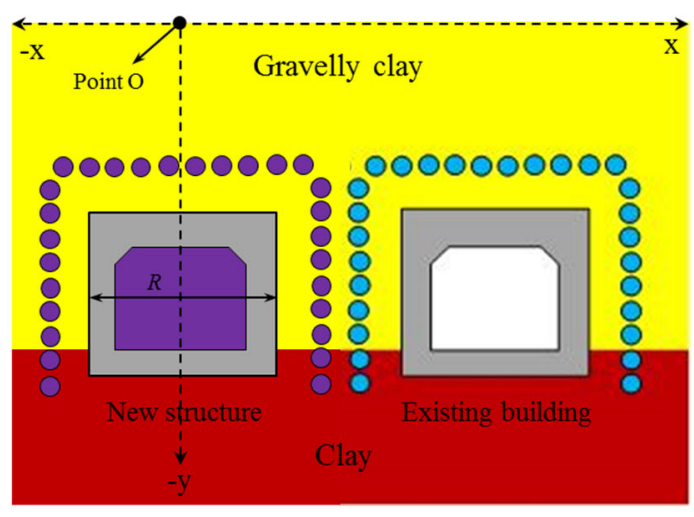

(a)

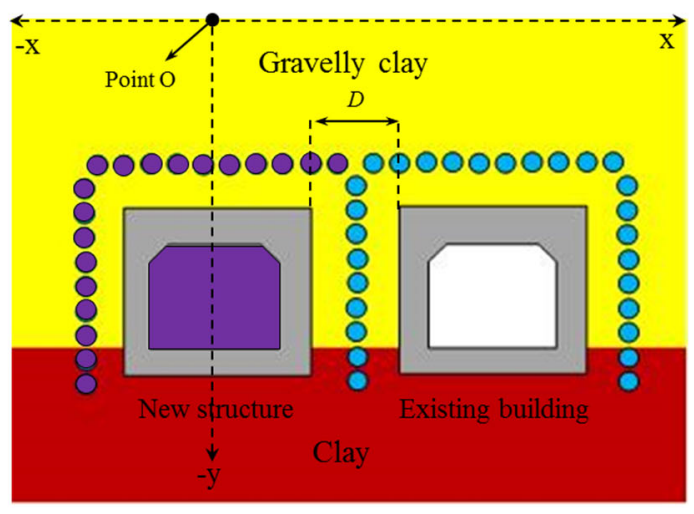

(b)

Fig. 2 Pipe roof gate and L-shaped system for the case of the new structure: (a) Pipe roof gate (b) L-shaped system

For the protection of the existing structure, the 28 roof pipelines were installed before the new tunnel construction. Considering the distance among structures that changes as abovementioned, the spacing of roof pipelines is fixed at $900 \mathrm{~mm}$. Relatively, the number of roof pipelines of the L-shaped system is changed from 19, 21, 23, 25, and 27 pipes accordingly. The ground surface's displacement was observed from the middle of the new structure. From the point $\mathrm{O}$, the displacement of the ground surface on the right side as well as the left side was analysed. It is referred to as negative direction and positive direction respectively to the $\mathrm{X}$-axis in the model. In this part, all analyses took only account of the displacement of the ground surface when the new structure was constructed.

Figure 3. presents the simulation results regarding the displacement of the ground surface with differences pipe roof supporting systems and distance between the new structure and existing building. The displacement of the ground surface is reduced by installing the pipe roofs and that clarified the pipe roof plays an important role as soil retaining wall when the new tunnel is excavated. The mechanism was proved in the previous research that the pipe roofs receive the ground pressure and balance the disturbance pressure from the excavation face of the new structure, consequently, the surface subsidence is minimized (Hisatake and Ohno 2008; Zheng et al. 2019). 
Distance from center of new structure $(\mathrm{m})$

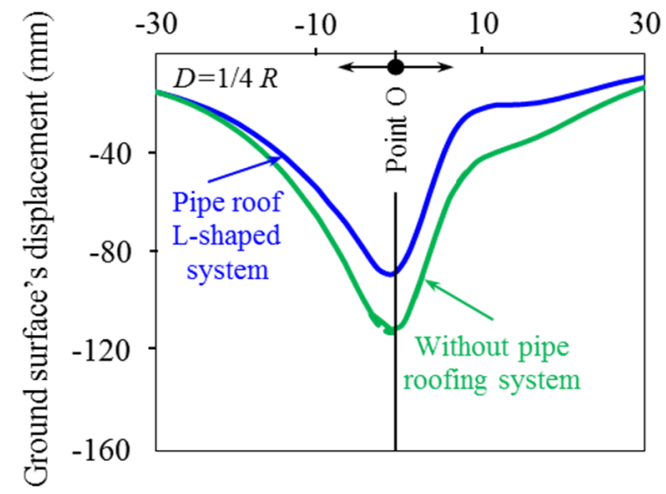

(a) $D=1 / 4 R$

Distance from center of new structure (m)

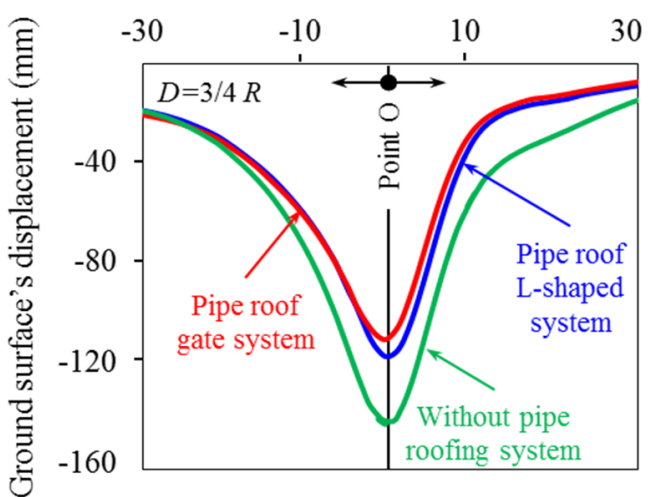

(c) $D=3 / 4 R$
Distance from center of new structure (m)

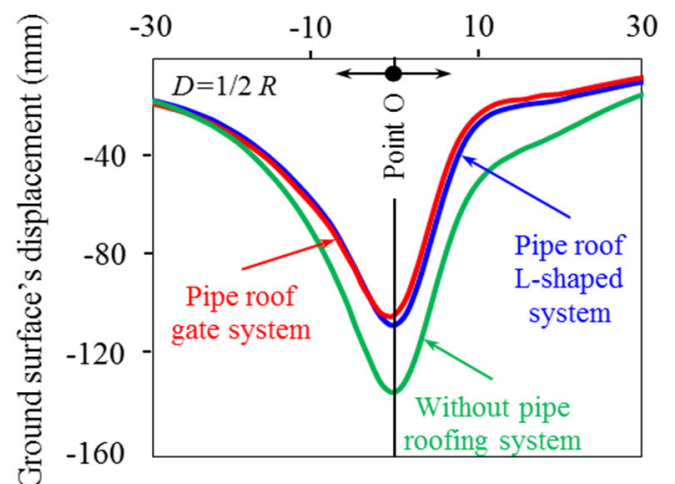

(b) $D=1 / 2 R$

Distance from center of new structure (m)

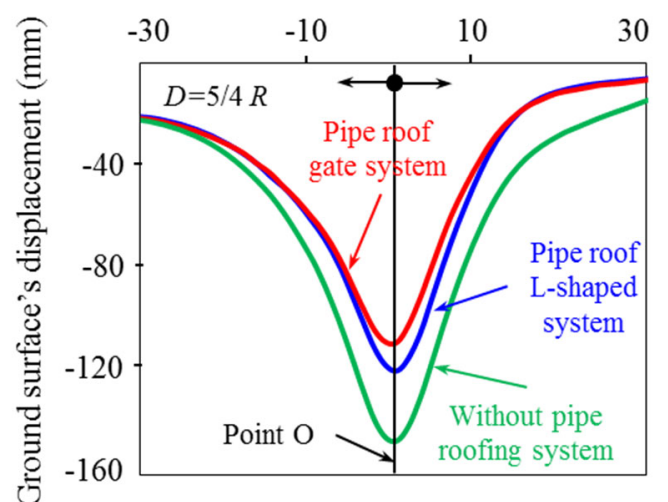

(d) $D=R$

Distance from center of new structure (m)

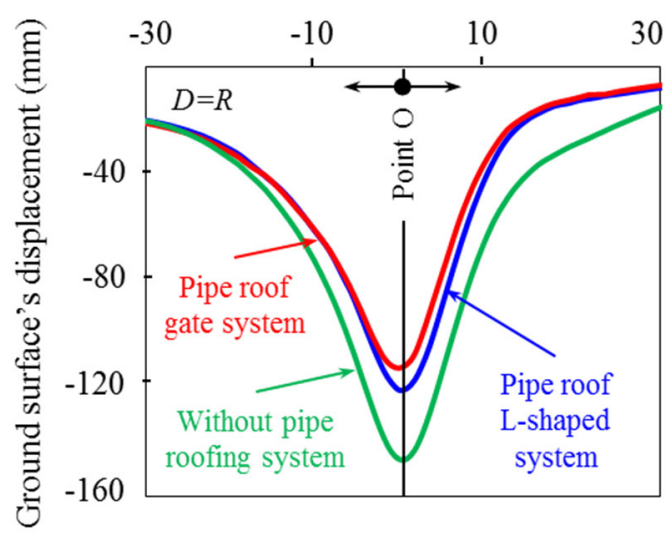

(e) $D=5 / 4 R$

Fig. 3 Displacement of the ground surface for the gate system and L-shaped system under different distances between the new structure and existing building.

It is also found that the displacement of the ground surface on the right side is more suppressed compared with the left side of the centre of the existing structure (observed from point $\mathrm{O}$ ). However, this suppressive effect of the existing building decreases with the widening of the distance between the new structure and existing building, which indicates that the existing building performs a function as a soil 
retaining wall and a partition wall for the new structure. The conclusion is consistent with the actual situation verified by the site monitoring (Sun et al., 2019).

In terms of the supporting effect of the pipe roof method, there is no obvious difference between the pipe roof gate system and pipe roof L-shaped system in regards to the surface subsidence when the distance is equal to half of the main tunnel's width $(D=1 / 2 R)$. When the distance is greater than or equal to $3 / 4 R$, the displacement of the ground surface of the L-shaped system is becoming larger than that of the gate system, particularly on the right side of the new structure. This is because, in the case of the Lshaped system, the distance between the new structure and the existing building is widened gradually which causes the diminishing of suppressive effect from the existing building. This also means the absence of pipes in the L-shaped system could cause more settlement as the $D$ increases.

While, in the case of the gate system, the new structure is covered by pipe roofs much well. Moreover, these pipe roofs are associated with their main tunnel, and thus it moves to follow the main tunnel. Notwithstanding the fact that, pipe roof gate system is more expensive in regards to installation cost than that of the L-shaped system. Therefore, it is suggested to adopt an L-shaped system when the distance between the new structure and the existing building is less than or equal to half of the main tunnel width due to fewer jacked pipes installation.

\subsection{Two structures constructed sequentially}

Under the condition of constructing underground structures sequentially, the displacement of the ground surface was simulated with the different distances between two structures. In this case, the structures and pipe roofs are constructed step by step as shown in Fig. 4. The distance was set set for 1/2 $R, R$, and $2 R$, respectively. The displacement of the ground surface was observed from the middle of two structures which is referred to as point $\mathrm{O}_{1}$. The gate system was applied to both structures as their pipe roofing system. In this simulation, the displacement caused by structure 1 and structure 2 is referred to as P1 and P2, respectively. While the displacement caused by both structures is referred to as P3. 56 pipelines were installed for two structures: 28 pipes attached to structure 1 and 28 pipes attached to structure 2. The results are presented in Fig. 5. 


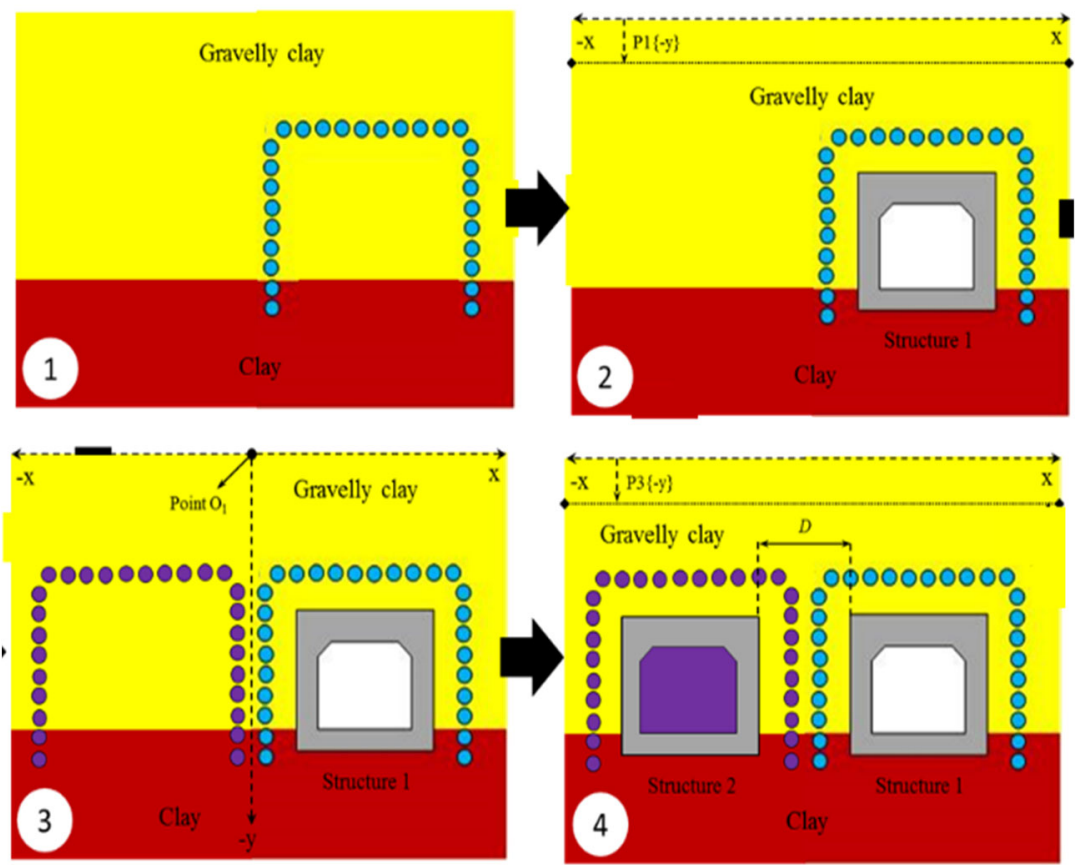

Fig. 4 Steps of construction in case of two structures are constructed sequentially.

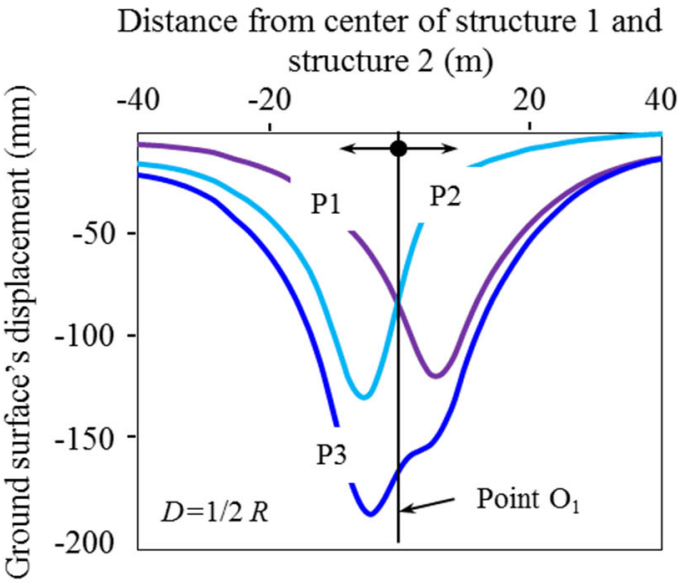

(a) $\mathrm{D}=1 / 2 \mathrm{R}$
Distance from center of structure 1 and structure $2(\mathrm{~m})$

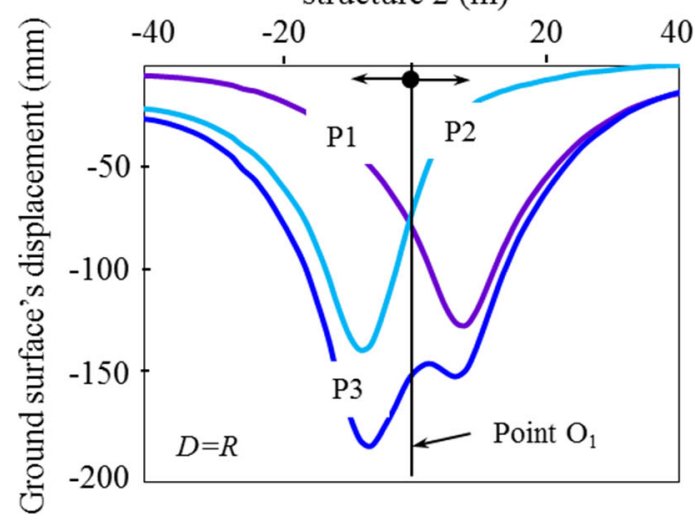

(b) $\mathrm{D}=\mathrm{R}$

Distance from center of structure 1 and structure $2(\mathrm{~m})$

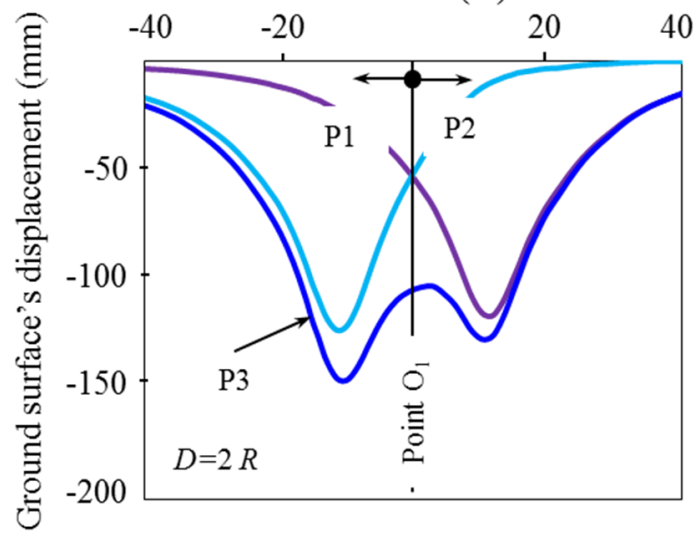

(c) $\mathrm{D}=2 \mathrm{R}$

Fig. 5 Ground surface displacement under two tunnels constructed sequentially. 
It can be confirmed from the results that the displacement of the ground surface increases with widening the value of the net distance $(D)$ from $1 / 2 R$ to $R$. However, the displacement of the ground surface decreases when $D$ is equal to $2 R$. One of the related reasons is that the reciprocal impact of those structures diminishing with $D$ increasing. Moreover, the results show that P3 is greater than P2, and P2 is greater than $\mathrm{P} 1$, as the excavation procedures of each tunnel influences each other reciprocally when structures are built close to each other. From the point of view of the maximum surface settlement, under the condition of two new tunnels constructed sequentially, the settlement was significantly greater than that of the one new tunnel built in the annex of the existing tunnel due to the superimposition of disturbances. The protective effect of the pipe roof method cannot be brought into full play, and it will still cause large settlement when the distance $(D)$ is less or equal to $R$. The results also show that constructing pipe roofs next to the existing structure can move the focus of ground pressure from the area of the existing structure to the construction area, which is also consistent with the results of on-site monitoring (Zhe Wang et al., 2019).

\subsection{Two structures constructed simultaneously}

In the following, the displacement of the ground surface with different spacing between the two tunnels was discussed. The rectangular tunnels were constructed simultaneously. For using the pipe roof method, there are two different designs could be used for pipe roofs installation: (1) one pipe roof system for both tunnels, as shown in Fig. 6 (a); (2) two-pipe roof system as a combination of the gate system and L-shaped system, as shown in Fig. 6 (b). The distance between two tunnels, $D$, was set for 1/2 $R, R$, $3 / 2 R$, and $2 R$; the corresponding numbers of installed pipelines were $41,44,49$, and 53 .

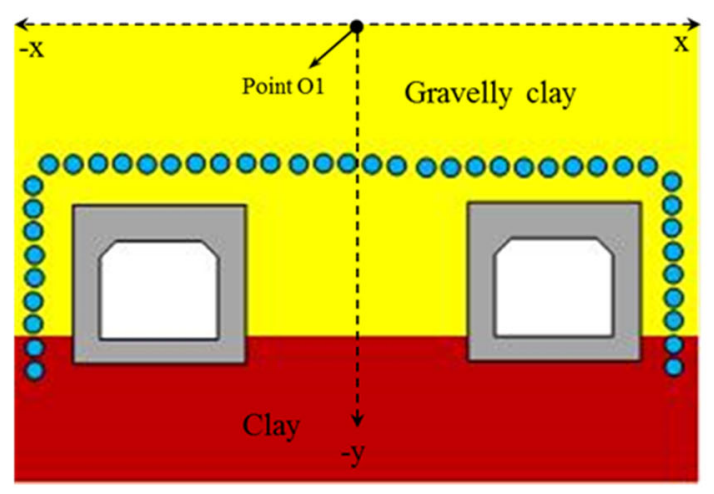

(a)

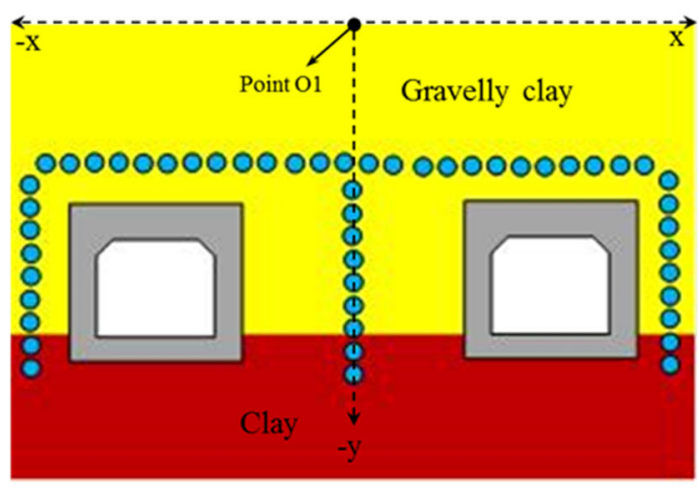

(b)

Fig. 6 Overview of the pipe roofing system when two structures are constructed simultaneously: (a) One pipe roofing system: pipe roof gate system; (b) Two pipe roofing system: pipe roof L-shaped system.

The displacement of the ground surface is illustrated in Fig. 7. Based on the results, increasing the 
distance between main tunnels could lead to the decreasing of displacement of the ground surface. The curves show that the reciprocal impact of each structure diminishes with the distance increasing, in other words, the displacement of the ground surface decreases with the distance increasing. Tunnels' construction influences each other mutually when two structures are constructed at the same time. Furthermore, the curves show that the displacement of the ground surface is more suppressed in the case of two pipe roofing systems compared with one pipe roofing system when $D$ is less than or equal to $R$. In general, it could be considered that pipe roofs which installed vertically between structures can play a role as the isolation wall to reduce the influence of the construction on the ground surface.

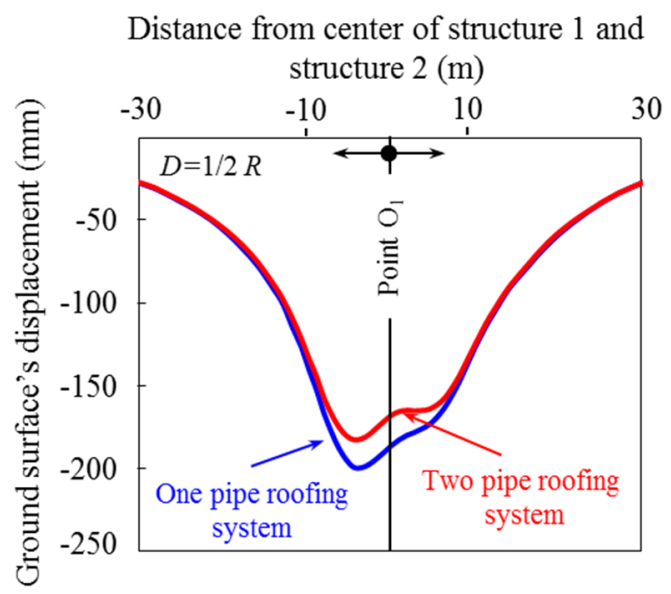

(a) $\mathrm{D}=1 / 2 \mathrm{R}$

Distance from center of structure 1 and

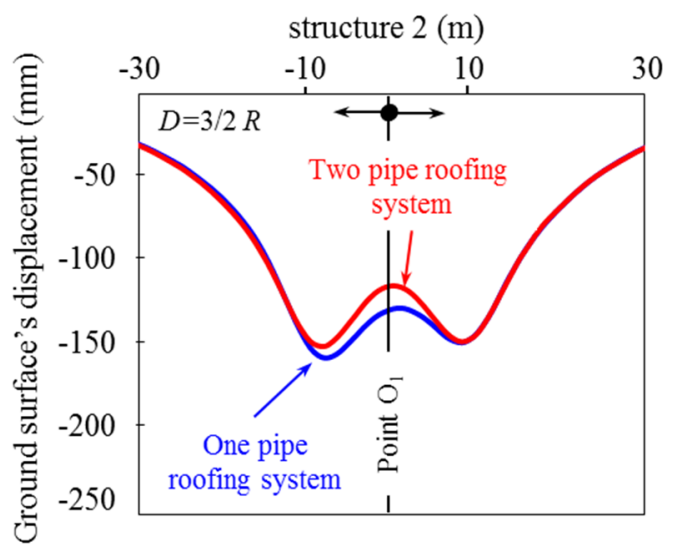

(a) $\mathrm{D}=3 / 2 \mathrm{R}$
Distance from center of structure 1 and

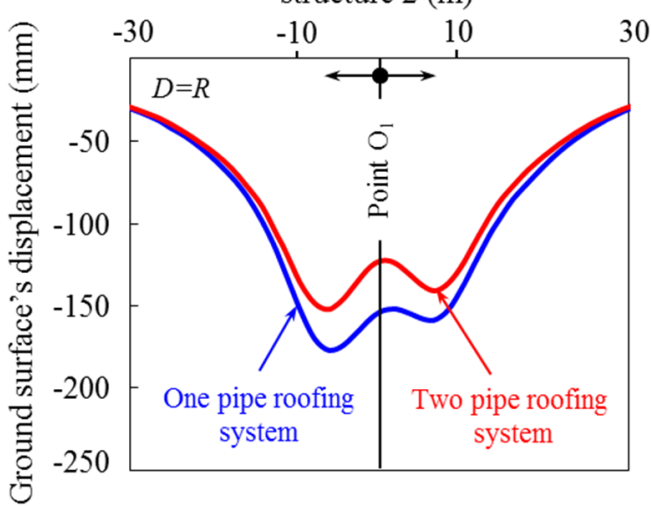

(b) $\mathrm{D}=\mathrm{R}$

Distance from center of structure 1 and

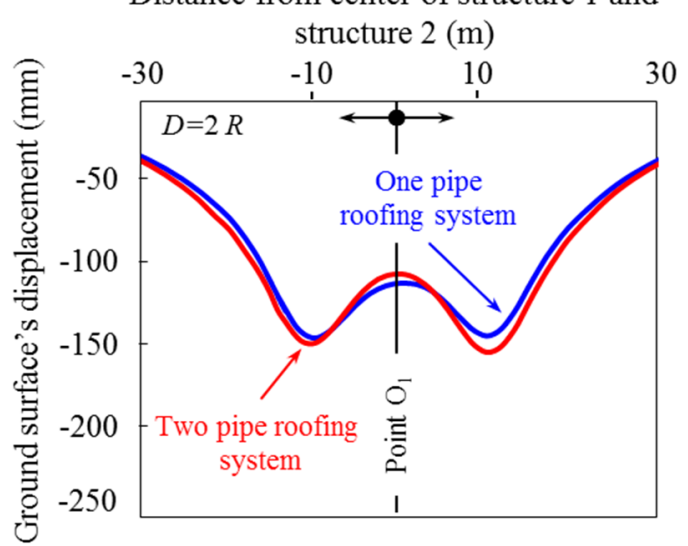

(b) $\mathrm{D}=2 \mathrm{R}$

Fig. 7 Displacement of the ground surface for any differences pipe roofing system for any distance between two structures when constructed simultaneously.

In this case, it is useful to adopt two pipe roof systems when $D$ is less than or equal to $R$. However, in case of $D$ is greater than or equal to $3 / 2 R$, there is almost no clear difference in regards to the displacement of the ground surface between one pipe roof system and two pipe roof systems, which illustrates that installing vertically pipelines between two structures does not give significant influence in surface displacement reduction. On the other hand, considering the amount of pipes consumption, two 
pipe roof systems are much more expensive than that of one pipe roof system, thus it is more economical to apply one pipe roof system instead of two pipe roofing systems when the distance between the two structures is over $2 R$. In summary, a suitable solution needs to balance the economic cost and engineering effect simultaneously.

\section{Conclusion}

Pipe roof method is an effective way to minimize the construction impact on the ground surface and adjacent buildings during the underground tunnelling in shallow or poor geological conditions. In this paper, pipe roof method was applied in the scenario of preservation of the adjacent building, and the performance of the different pipe roofs disposition schemes with pipe roof gate system and L-shaped system was investigated in terms of ground displacement in the rectangular underground space construction. Based on the above discussion, it is suggested:

(1) When a new structure is constructed nearby the existing building, it is useful to adopt a pipe roof L-shaped system in case $D$ is less than or equal to $1 / 2 R$.

(2) The excavation procedures of each tunnel influences each other reciprocally when structures are built sequentially. While the ground surface displacement increases with widening the value of the net distance $(D)$ from $1 / 2 R$ to $R$. However, the displacement of the ground surface decreases when $D$ is equal to $2 R$.

(3) When two structures are constructed simultaneously, it is necessary to choose a suitable pipe roof disposition scheme according to the economic cost and actual effect. Specifically, the displacement of the ground surface increases with the distance decreasing. Additionally, it is useful to adopt two pipe roof system in case of $D$ is less than or equal to $R$. However, when $D$ is greater than or equal to $3 / 2 R$, it is more economical to adopt one pipe roof system.

This study found that the appropriate pipe roof method could reduce the construction impacts on the existing underground facilities during a new structure construction, and it also could control the ground surface settlement effectively.

\section{Acknowledgments}

The authors confirm that there are no conflicts of interest associated with this publication and there is no significant financial support for this work that could have influenced its outcome. 


\section{References}

Bae GJ, Shin HS, Sicilia C, et al (2005) Homogenization framework for three-dimensional elastoplastic finite element analysis of a grouted pipe-roofing reinforcement method for tunnelling. Int J Numer Anal Methods Geomech 29:1-24. https://doi.org/10.1002/nag.402

Coller PJ, Abbott DG (1994) Microtunneling techniques to form an insitu barrier around existing structures. High Lev Radioact Waste Manag - Proc Annu Int Conf 2:386-394

Fang C, Sun J (2000) Ground movements induced by pipe jacking in shallow underground soils. Yantu Lixue/Rock Soil Mech

Hisatake M, Ohno S (2008) Effects of pipe roof supports and the excavation method on the displacements above a tunnel face. Tunn Undergr Sp Technol 23:120-127. https://doi.org/10.1016/j.tust.2007.02.002

Hu X-D, Fang T, Guo X-D, Ren H (2017) Temperature field research on thawing process of FreezeSealing Pipe Roof Method in Gongbei Tunnel by in-situ prototype test. Meitan Xuebao/Journal China Coal Soc 42:. https://doi.org/10.13225/j.cnki.jccs.2016.1246

Japan Tunnelling Association (1995) Challenges and changes: Tunnelling activities in Japan 1994. Tunn Undergr Sp Technol Inc Trenchless 10:203-215. https://doi.org/10.1016/08867798(95)00008-m

Jia PJ, Zhao W, Chen Y, et al (2018) A case study on the application of the Steel Tube Slab structure in construction of a subway station. Appl Sci 8. https://doi.org/10.3390/app8091437

Khazaei S, Shimada H, Kawai T, et al (2006) Monitoring of over cutting area and lubrication distribution in a large slurry pipe jacking operation. Geotech Geol Eng 24:735-755. https://doi.org/10.1007/s10706-004-5436-1 
Mark Marshall (1998) Pipe-jacked tunnelling: jacking loads and ground movements. PhD Thesis, University of Oxford, Oxfordshire, England.

Oliver MI, Boland D, MacCormick MJ, Bower JC (2006) Major pipe jacking for Perth desalination and main sewer projects. Australas Soc Trenchless Technol - 24th No-Dig Int Conf Exhib No-Dig Down Under 2006 472-480

Peng Zhang, Xiang-Yu Wang, Cong Zeng, Bao-Song MA (2016) Site monitoring of mechanical characteristics of pipes during steel curved pipe jacking under large buried depth. Chinese Journal of Geotechnical Engineering 38: 1842-1848. DOI: 10.11779/CJGE201610013.

Shimada H, Khazaei S, Matsui K (2004) Small diameter tunnel excavation method using slurry pipejacking. Geotech Geol Eng 22:161-186. https://doi.org/10.1023/B:GEGE.0000018365.84174.ea

Sun Y, Wu F, Sun W, et al (2019) Two underground pedestrian passages using pipe jacking: Case study. J Geotech Geoenvironmental Eng 145:1-8. https://doi.org/10.1061/(ASCE)GT.19435606.0002006

Volkmann GM, Schubert W (2007) Geotechnical model for pipe roof supports in tunneling. "Proceedings 33rd ITA-AITES World Tunn Congr - Undergr Sp - 4th Dimens Metropolises" 1:755-760. https://doi.org/10.1201/noe0415408073.ch125

Wang H, Ha J (2008) Analytical method for mechanical behaviors of pipe roof reinforcement. In: Proceedings of the international conference on information management, innovation management and industrial engineering, Vol III. IEEE Computer Soc, 10662 Los Vaqueros Circle, Po Box 3014, Los Alamitos, CA 90720-1264 USA, pp 352-357

Wang H, Jiang Y, Xue S, et al (2015) Assessment of excavation damaged zone around roadways under dynamic pressure induced by an active mining process. Int J Rock Mech Min Sci 77:265-277. 
https://doi.org/10.1016/j.ijrmms.2015.03.032

Wang Z, Hu Z, Lai J, et al (2019) Settlement Characteristics of Jacked Box Tunneling underneath a Highway Embankment. J Perform Constr Facil 33: https://doi.org/10.1061/(ASCE)CF.19435509.0001269

Xiangdong Hu, Tao Fanf (2017) Temperature field research on thawing process of Freeze-Sealing Pipe roof Method in Gongbei Tunnel by in-situ prototype test, Journal of China Society:42( 7): 17001705.doi: $10.13225 /$ j.cnki.jccs.2016.1246

Xiao H, Zhou S, Sun Y (2019) Stability Analysis and Case Study of Shallow Tunnel Using Pipe Roof Support. Geotech Geol Eng 37:1249-1260. https://doi.org/10.1007/s10706-018-0681-x

Xiao SG, Xia CC, Li XY, et al (2005) Experimental study on coefficient of friction between a box culvert and mixture composed of thixotropic slurry and clay or steel pipe during culvert being pushed by pipe-roof. Yanshilixue Yu Gongcheng Xuebao/Chinese J Rock Mech Eng 24:27462750

Yen J, Shou K (2015) Numerical simulation for the estimation the jacking force of pipe jacking. Tunn Undergr Sp Technol. https://doi.org/10.1016/j.tust.2015.04.018

Zheng C, Ping H, Du-min Y, Hong-jie G (2019) A method to calculate rational spacing between pipes in pipe roofs considering soil arching effects. ROCK SOIL Mech 40:1993-2000. https://doi.org/10.16285/j.rsm.2018.1268 